\title{
Comparison of the ionic currents modulated during activity-dependent and normal presynaptic facilitation
}

\author{
Robert D. Hawkins ${ }^{1,2}$ and Eric R. Kandel ${ }^{1,2,3}$ \\ ${ }^{1}$ Department of Neuroscience, Columbia University, New York, New York 10032, USA; ${ }^{2}$ Division of Systems Neuroscience, New York \\ State Psychiatric Institute, New York, New York 10032, USA; ${ }^{3}$ Howard Hughes Medical Institute, New York, New York 10032, USA
}

\begin{abstract}
One of the major questions in psychology is whether associative and nonassociative learning are fundamentally different or whether they involve similar processes and mechanisms. We have addressed this question by comparing mechanisms of a nonassociative form of learning, sensitization, and an associative form of learning, classical conditioning of the siphon-withdrawal reflex of hermaphroditic Aplysia. In an analog of differential conditioning, action potentials in one siphon sensory neuron (SN) were paired with shock to the pedal nerves, producing activity-dependent presynaptic facilitation, and action potentials in another $\mathrm{SN}$ were unpaired with the shock as a control. The difference between paired and unpaired training is a measure of associative plasticity. Before and after this training, we voltage clamped each $\mathrm{SN}$ and measured the outward current during depolarizing pulses. There was a significantly greater decrease in the net outward current in the paired SN than in the unpaired SN. We obtained similar results when we substituted the depolarizing voltage clamp pulse for action potentials during training. We then bathed the ganglion in serotonin as a measure of nonassociative plasticity. The current that was modulated differentially (paired-unpaired) had time and voltage dependencies similar to the current that was modulated by serotonin $\left(I_{s}\right)$. These results suggest that an associative form of plasticity, activity-dependent presynaptic facilitation underlying conditioning, involves enhanced modulation of the same ionic current as a nonassociative form, normal presynaptic facilitation underlying sensitization.
\end{abstract}

One of the major questions in psychology is whether associative and nonassociative learning are fundamentally different or whether they involve similar processes and mechanisms. We have taken a reductionist approach to this question by comparing mechanisms of a nonassociative form of learning, sensitization, and an associative form of learning, classical conditioning of the siphonwithdrawal reflex of Aplysia, using in vivo, semi-intact, and in vitro preparations (for reviews, see Hawkins and Byrne 2015; Hawkins et al. 2017). The gill- and siphon-withdrawal reflex of Aplysia exhibits sensitization in response to the tail shock, and classical conditioning when a weak stimulus to the siphon or mantle (the conditioned stimulus or CS) is paired with tail shock (the unconditioned stimulus or US). Sensitization involves serotonin- and cAMP-dependent presynaptic facilitation at the synapses from siphon sensory neurons (SNs) to gill- and siphon-motor neurons, due in part to broadening of action potentials in the SNs and enhanced transmitter release. Classical conditioning involves activity-dependent amplification of that mechanism when action potentials in the $\mathrm{SN}$ are paired with the shock.

The first experiments to demonstrate this mechanism used the preparation illustrated in Figure 1A, which consists of the isolated nervous system attached to the tail by the posterior pedal nerves. A training procedure based on that used to produce differential conditioning of the withdrawal reflex behaviorally also produced differential facilitation of the EPSPs from two siphon SNs to a siphon motor neuron (Hawkins et al. 1983). During training, action potentials in one $\mathrm{SN}$ were paired with shock to the tail or pedal nerves, and action potentials in the other $\mathrm{SN}$ were unpaired. This procedure produced significantly greater facilitation of the EPSP from the paired than from the unpaired $\mathrm{SN}$, which we referred to as activity-dependent facilitation. In similar experiments, this training procedure also produced greater broadening of the action

\section{Corresponding author: rdh1@columbia.edu}

Article is online at http://www.learnmem.org/cgi/doi/10.1101//m.049916.119. potential in the paired than the unpaired SN, either in a TEA or in normal seawater. These results suggested that a mechanism of conditioning was an amplification of the mechanism of sensitization.

However, subsequent experiments have revealed additional pre- and postsynaptic mechanisms, some of which are shared by sensitization and conditioning and some of which are unique to conditioning, raising questions about their relationship (Hawkins and Byrne 2015; Hawkins et al. 2017). Furthermore, broadening of action potentials in the $\mathrm{SN}$ might be due to changes in several different ionic currents. If conditioning involves amplification of a mechanism of sensitization, then activity-dependent facilitation should involve modulation of the same ionic current as normal presynaptic facilitation. Normal presynaptic facilitation involves a decrease in two $\mathrm{K}+$ currents, a voltage-dependent current, $I_{\mathrm{KV}}$, and a serotonin- and cyclic AMP-sensitive current, $I_{\mathrm{S}}$, which is also important for an increase in $\mathrm{SN}$ excitability during facilitation (Klein et al. 1982; Shuster et al. 1985; Baxter and Byrne 1989; Goldsmith and Abrams 1992; Hochner and Kandel 1992; Byrne and Kandel 1996). We have now investigated whether activity-dependent facilitation involves modulation of the same currents. Because there are pairing-specific increases in $\mathrm{SN}$ excitability as well as facilitation of the EPSP during behavioral conditioning (Antonov et al. 2001, 2003, 2007), we have focused on $I_{S}$.

\section{Results}

The training procedure was identical to that used in the experiments demonstrating activity-dependent facilitation of the EPSP

(C) 2019 Hawkins and Kandel This article is distributed exclusively by Cold Spring Harbor Laboratory Press for the first 12 months after the full-issue publication date (see http://learnmem.cshlp.org/site/misc/terms.xhtml). After 12 months, it is available under a Creative Commons License (AttributionNonCommercial 4.0 International), as described at http://creativecommons. org/licenses/by-nc/4.0/. 
A
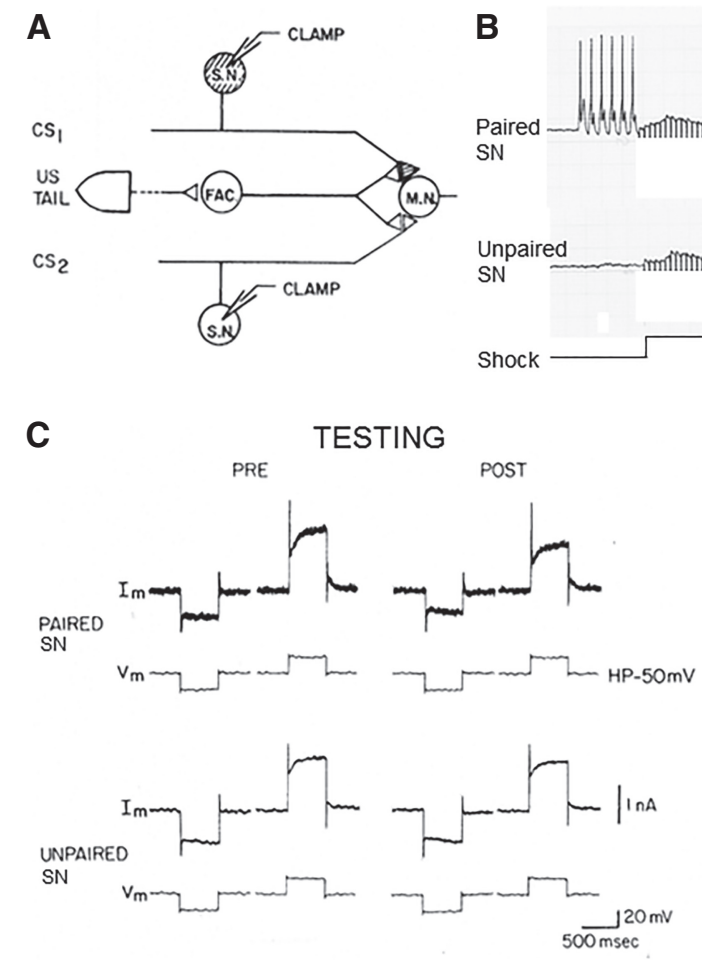

B

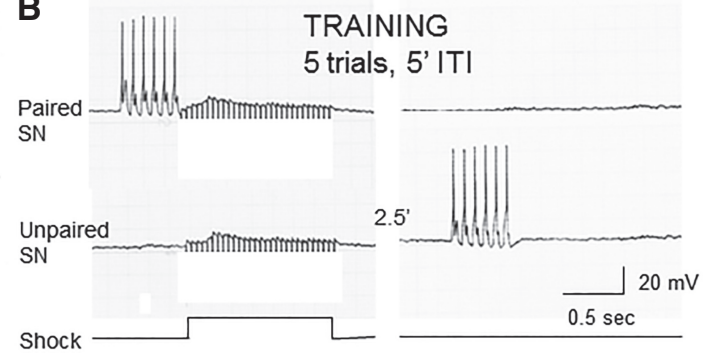

D

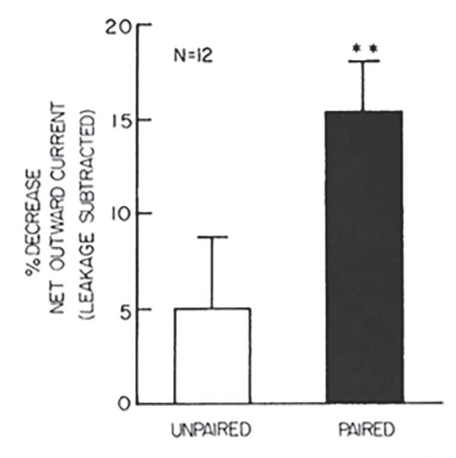

Figure 1. A training procedure for differential facilitation in Aplysia produces a differential decrease in an outward current in the SNs. $(A)$ The experimental preparation. (B) An example of one training trial in which a brief train of action potentials in the paired $\mathrm{SN}$ started $0.5 \mathrm{sec}$ before shock to the posterior pedal nerves (indicated by the shock artifacts) and a train of action potentials in the unpaired SN started 2.5 min later. There were five training trials with a $5 \mathrm{~min}$ ITI. (C) An example of testing $5 \mathrm{~min}$ before (Pre) and after (Post) training. We measured the outward current in each SN during a $500 \mathrm{msec}, 20 \mathrm{mV}$ depolarizing voltage clamp pulse from a holding potential of $-50 \mathrm{mV}$. We also measured the inward current during a $20 \mathrm{mV}$ hyperpolarizing pulse as an estimate of the leakage current, which was subtracted from the outward current to give an estimate of the net voltage-dependent current. $(D)$ Average results from 12 experiments like the one shown in $C$. There was a significantly greater decrease in the net outward current in the paired than the unpaired SN after training.

(Fig. 1A,B; Hawkins et al. 1983). There were five training trials with a 5 min intertrial interval. On each trial, we produced a train of six action potentials at $10 \mathrm{~Hz}$ in the paired SN starting $0.5 \mathrm{sec}$ before shock to the posterior pedal nerves, and a train of action potentials in the unpaired SN starting 2.5 min later. The train of action potentials was similar to the firing of the $\mathrm{SN}$ during behavioral training in a semi-intact preparation (Antonov et al. 2001, 2003, 2007). However, now instead of measuring the amplitudes of the EPSPs from each SN to a motor neuron, we voltage clamped each SN with a Dagan single electrode clamp and measured the outward current during $500 \mathrm{msec}, 20 \mathrm{mV}$ depolarizing pulses from a holding potential of $-50 \mathrm{mV}, 5 \mathrm{~min}$ before and after training (Fig. 1C). Training and testing were both carried out in normal artificial seawater. We also measured the inward current during hyperpolarizing voltage clamp pulses as an estimate of leakage current, which was subtracted from the outward current to give an estimate of the net voltage-dependent current. In the example shown in Figure 1C, there was a substantial decrease in the outward current in the paired SN, and a much smaller decrease in the unpaired SN. In 12 experiments like that one, there was a significantly greater decrease in the net outward current in the paired than the unpaired SNs $\left(t_{(11)}=3.15, P<0.01\right)$ (Fig. 1D). As controls, there was no significant difference in the baseline resting potential (average $=$ $-44 \mathrm{mV}$ ), drift in the holding potential as measured at the end of the experiment (average $=-54 \mathrm{mV}$ ), pretest depolarizing and leakage currents, or the change in leakage current following training.
The parameters of the depolarizing voltage clamp pulse, which was relatively small and long lasting, were chosen on the basis of previous experiments (Klein et al. 1982; Shuster et al. 1985; Baxter and Byrne 1989; Goldsmith and Abrams 1992; Hochner and Kandel 1992) so that most of the outward current would be carried by $I_{\mathrm{S}}$. We further tested that hypothesis by comparing the time and voltage dependence of the current that is modulated differentially to the time and voltage dependence of $I_{\mathrm{S}}$. At the end of each experiment, we exposed the ganglion to $10^{-4} \mathrm{M}$ serotonin (which produces a near maximal decrease in $I_{\mathrm{S}}$ ) and measured the currents again. We then compared that current to the current that was modulated by paired and unpaired training in the same cells. To do this, we looked at the "difference" current, or the Pre-Post change in current produced by the training procedure. The results from the experiment illustrated in Figure 1C are plotted in Figure 2A, which shows the difference current in the paired cell, the unpaired cell, and the average response to serotonin in both cells as a function of time during the $500 \mathrm{msec}$ depolarizing pulse. The magnitude of the difference current is different in the three cases but the curves have similar shapes, indicating that the currents have similar time dependence.

Figure $2 \mathrm{~B}$ shows the current that is modulated differentially, that is, the current in the paired cell minus the current in the unpaired cell, which is a measure of associative plasticity, plotted on a different scale to facilitate comparison with the current that is modulated by serotonin, which is a measure of nonassociative plasticity. The time dependence of these two currents is very similar. In particular, neither shows appreciable inactivation within $500 \mathrm{msec}$, which is a distinguishing feature of $I_{\mathrm{S}}$. These results support the idea that the differential training procedure produces a differential decrease in $I_{S}$.

As the second test of that idea, we have begun to examine the voltage dependence of the current that is modulated differentially in these experiments by measuring that current during $40 \mathrm{mV}$ as well as $20 \mathrm{mV}$ depolarizing pulses before and after training and also after serotonin in each of the experiments shown in Figure 1 . The average results from those experiments are illustrated in Figure 3. Figure 3A shows the Pre-Post difference current (corrected for changes in leakage) at the two levels of depolarization from a holding potential of $-50 \mathrm{mV}$ in paired cells, unpaired cells, and all cells following exposure to serotonin. There were significant effects of training $\left(F_{(2,22)}=37.45, P<0.001\right)$, voltage step $\left(F_{(1,11)}=19.62, P<0.001\right)$ and the training by voltage step interaction $\left(F_{(2,22)}=27.88, P<0.001\right)$ in a repeated-measures ANOVA. Furthermore, the three curves have similar shapes, and the interaction became nonsignificant $(F=0.00, P>0.99)$ when the curves were scaled to the same overall mean. These results indicate that the currents have similar voltage dependence in this range.

Figure 3B shows the current that is modulated associatively or differentially in these experiments, that is the current in the paired cell minus the current in the unpaired cell. Again, compared with 

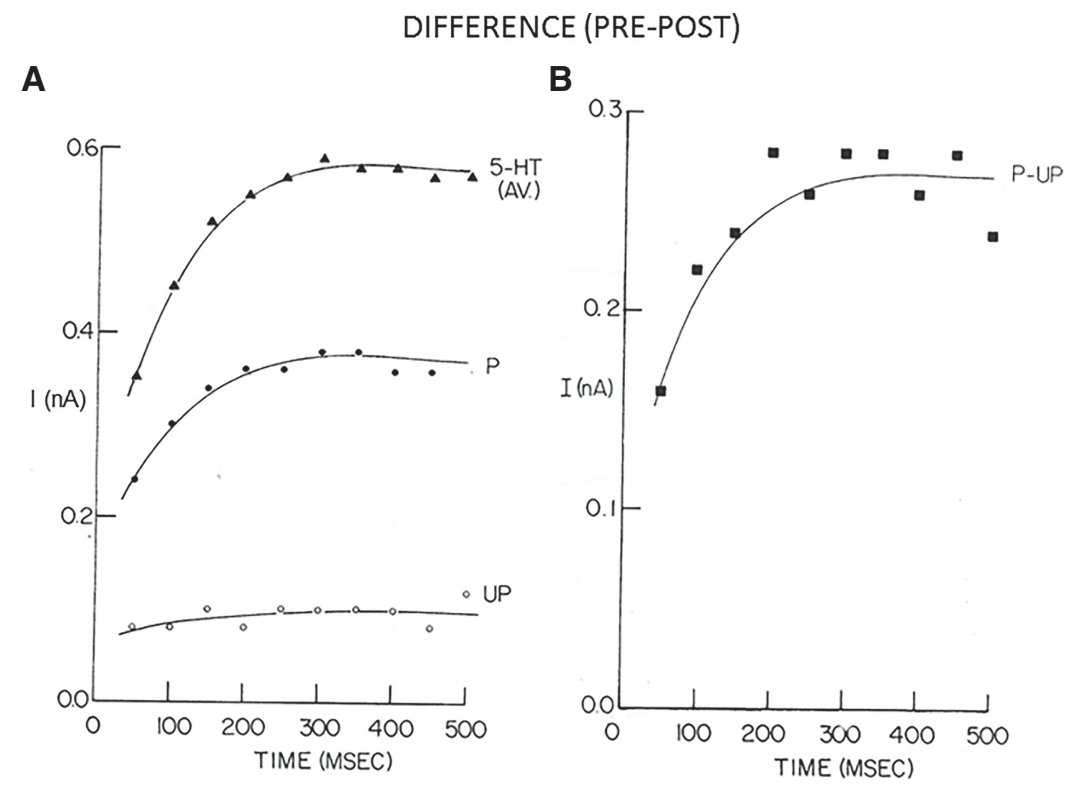

Figure 2. Time dependence of the current that is modulated associatively or differentially, compared with the current that is modulated nonassociatively by serotonin. $(A)$ Graph of the Pre-Post difference current as a function of time during the 500 msec depolarizing pulse in the paired and unpaired $\mathrm{SN}$, and then measured again in both neurons after adding $10^{-4} \mathrm{M}$ serotonin to the bath. The response to serotonin would be expected to have similar properties in both neurons, which were, therefore, averaged to provide a better estimate. (B) Graph of the current that is modulated differentially (Paired-Unpaired) as a function of time. The shape of that curve is very similar to the curve for the current that is modulated by serotonin, indicating that those currents have similar time dependence in this range.

the current that is modulated nonassociatively by serotonin there were significant effects of training $\left(F_{(1,11)}=33.38, P<0.001\right)$, voltage step $\left(F_{(1,11)}=26.39, P<0.001\right)$ and the training by voltage step interaction $\left(F_{(1,11)}=23.91, P<0.001\right)$. Furthermore, the two curves have similar shapes, and the interaction became nonsignificant $(F=0.00, P>0.99)$ when they were scaled to the same overall mean. These results indicate that the voltage dependence of the current that is modulated associatively (P-UP) is very similar to that of the current that is modulated nonassociatively by serotonin. In particular, both currents are turned on in the range of -50 to $-30 \mathrm{mV}$, meaning that they are turned on at the resting potential, and both have modest nonlinearity with increasing depolarization. There was a trend for the current that is modulated by serotonin (Pre-5HT) to be more occluded (Post-5HT) following paired than unpaired training. However, the two were not significantly different and would be expected to have the same voltage dependence, and therefore have been pooled. These results provide further support for the idea that an associative form of plasticity, activity-dependent presynaptic facilitation, involves modulation of the same ionic current as a nonassociative form, normal presynaptic facilitation.

Another question concerning the relationship between associative and non-

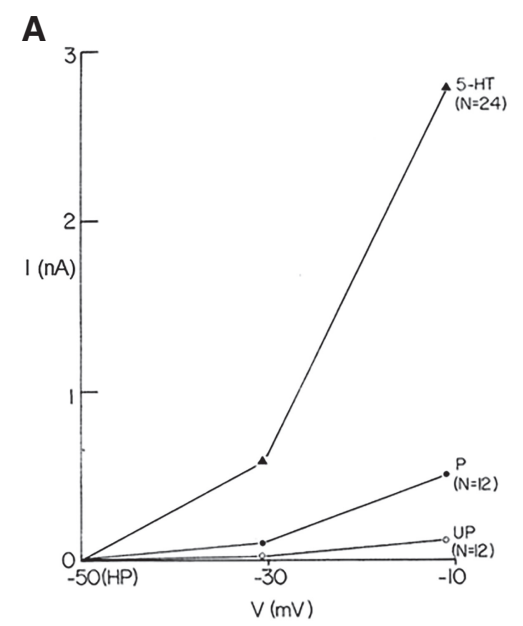

associative plasticity is what properties of the CS are necessary to produce associative plasticity? In these and previous experiments on activity-dependent facilitation the CS was a brief train of action potentials in the SN (Hawkins et al. 1983; Walters and Byrne 1983; Clark et al. 1994; Eliot et al. 1994; Schacher et al. 1997; Bao et al. 1998), designed to mimic what happens during behavioral conditioning (Antonov et al. 2001, 2003). We asked whether the same depolarizing voltage clamp pulse that we used to measure the current before and after training might also act as the CS during training. The protocol was identical to that shown in Figure 1B except that now, instead of a train of six action potentials in the $\mathrm{SN}$ on each training trial, there was a $500 \mathrm{msec}, 20$ or $40 \mathrm{mV}$ depolarizing voltage-clamp current pulse in the paired SN starting $0.5 \mathrm{sec}$ before pedal nerve shock, and a pulse in the unpaired $\mathrm{SN}$ 2.5 min later (Fig. 4A). In 12 experiments with this protocol, there was a significantly greater decrease in the net outward current in the paired than in the unpaired $\mathrm{SN}$ following training $\left(t_{(11)}=\right.$ 3.46, $P<0.01$ ) (Fig. 4B). This differential decrease was significant with either a $20 \mathrm{mV}(P<0.05)$ or $40 \mathrm{mV}(P<0.05$ onetail) pulse as the CS, although there was a trend for a greater differential decrease with the $40 \mathrm{mV}$ pulse $(12.8 \pm 4.7 \%$ vs. $21.3 \pm 8.8 \%)$. These results replicate the results shown in Figure 1 and indicate that action potentials are not necessary, but rather a 20 or $40 \mathrm{mV}$ depolarizing voltage clamp pulse can act as the CS during activitydependent facilitation.

\section{DIFFERENCE (PRE-POST)}

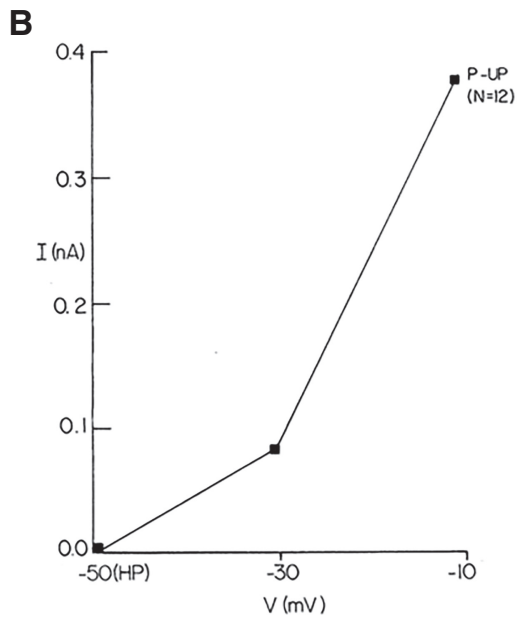

Figure 3. Voltage dependence of the current that is modulated associatively or differentially, compared with the current that is modulated nonassociatively by serotonin. $(A)$ Graph of the Pre-Post difference current (corrected for leakage) during 20 and $40 \mathrm{mV}$ depolarizing pulses in the paired and unpaired $\mathrm{SN}$, and then measured again in all neurons after adding $10^{-4} \mathrm{M}$ serotonin to the bath. (B) Graph of the current that is modulated differentially (Paired-Unpaired) as a function of voltage. The shape of that curve is very similar to the curve for the current that is modulated by serotonin, indicating that those currents have similar voltage dependence in this range. 
A

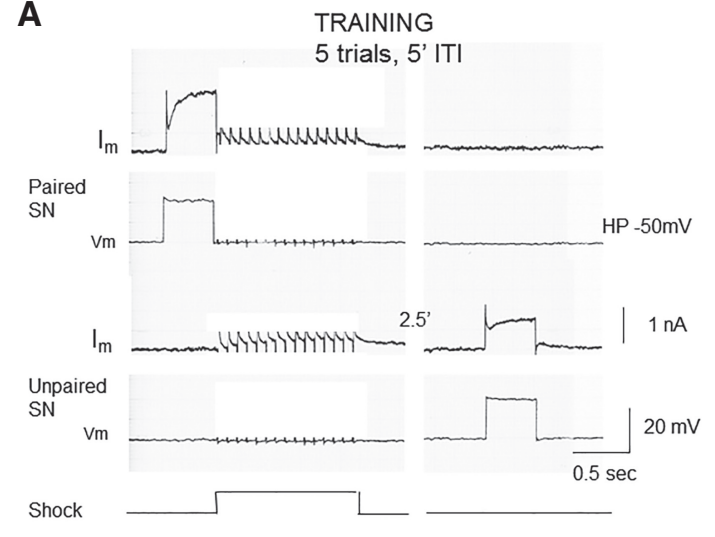

B

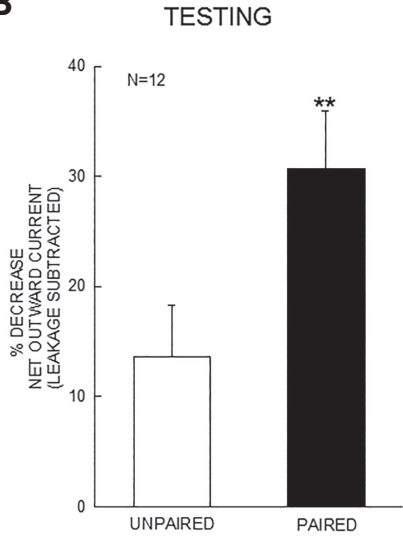

Figure 4. The depolarizing voltage clamp pulse can also act as the CS during training. (A) Example of a training trial with a $500 \mathrm{msec}, 20 \mathrm{mV}$ depolarizing voltage clamp pulse as the paired and unpaired CS instead of a brief train of action potentials. $(B)$ Average testing results from 12 experiments like the one shown in $A$. There was a significantly greater decrease in the net outward current in the paired than the unpaired $\mathrm{SN}$ after training with a depolarizing voltage clamp pulse as the CS.

\section{Discussion}

Our results support the idea that associative and nonassociative plasticity share cellular and molecular mechanisms, and are therefore not fundamentally different. More specifically, the results support the hypothesis that activity-dependent presynaptic facilitation, an associative form of plasticity that contributes to classical conditioning in Aplysia, involves amplification of the mechanisms of normal presynaptic facilitation, a nonassociative form that contributes to sensitization, and that they both involve modulation of the same ionic current in the SNs. Some of the early studies of associative and nonassociative plasticity in Aplysia found that they both involve serotonin, cAMP, and PKA-dependent facilitation of EPSPs at the SN-motor neuron synapses and also broadening of action potentials and an increase in membrane resistance of the SNs, all of which are larger during associative plasticity (Hawkins et al. 1983; Walters and Byrne 1983; Clark et al. 1994; Eliot et al. 1994; Bao et al. 1998; Antonov et al. 2001, 2003). Subsequent studies of associative and nonassociative plasticity have found that they also both involve sensorin synthesis and secretion (Hu et al. 2007), neurotrophin signaling, RNA synthesis, and DNA methylation (Yang et al. 2018), and PKM Apl II in the SN (Hu et al. 2017a). However, other studies have found mechanisms that are unique to associative plasticity including Hebbian potentiation initiated by $\mathrm{Ca}^{2+}$ influx through postsynaptic NMDA receptor channels (Lin and Glanzman 1994a,b; Murphy and Glanzman 1996, 1997, 1999; Schacher et al. 1997; Bao et al. 1998; Antonov et al. 2003), which are modulated by NO and Ih (Antonov et al. 2007; Yang et al. 2015). Furthermore, these pre- and postsynaptic mechanisms interact through retrograde signaling (Bao et al. 1998; Antonov et al. 2003). In addition, associative and nonassociative plasticity involve different kinases in the $\mathrm{SN}$ (Hu et al. 2007) and different calpains and PKM isoforms in the SN and motor neuron (Hu et al. 2017a,b).

These results suggest that associative and nonassociative plasticity have both shared and unique mechanisms, raising questions about the relationship between the two types of plasticity. Furthermore, one of the mechanisms that is thought to be shared, spike broadening in the SNs, could actually involve modulation of different ionic currents during the different forms of plasticity and therefore be unique to one of them. We have investigated that possibility, and have found that activity-dependent facilitation appears to involve modulation of the same serotonin-sensitive current, $I_{\mathrm{S}}$, as normal presynaptic facilitation. That result is consistent with the finding that serotonin can serve as the US for activity-dependent facilitation (Clark et al. 1994; Eliot et al. 1994; Schacher et al. 1997; Bao et al. 1998), and supports the idea that associative and nonassociative plasticity involve at least some shared mechanisms.

Classical conditioning requires that an US such as shock be temporally paired with and contingent on a CS during training, whereas sensitization does not involve a CS during training. What properties of a stimulus are necessary for it to be able to act as a CS for conditioning? All previous studies of activity-dependent facilitation have used a train of action potentials in the SN (Hawkins et al. 1983; Walters and Byrne 1983; Clark et al. 1994; Eliot et al. 1994; Schacher et al. 1997; Bao et al. 1998). We found that a 20 or $40 \mathrm{mV}$ depolarizing voltage clamp pulse could substitute for the train of action potentials as the CS. If the $20 \mathrm{mV}$ pulse caused relatively little transmitter release these results would imply that postsynaptic receptor activation may not be required for the presynaptic changes in $I_{\mathrm{S}}$, although it is thought to contribute (Bao et al. 1998; Antonov et al. 2003). Similarly, Hebbian potentiation is traditionally said to require coincident pre- and postsynaptic action potentials, but postsynaptic depolarization can substitute for the postsynaptic action potentials (Wigström et al. 1986; Kelso et al. 1986).

During activity-dependent facilitation the CS is thought to allow an influx of $\mathrm{Ca}^{2+}$ that primes an adenylyl cyclase coupled to the serotonin receptor, so that it produces more cAMP if serotonin arrives in the next second or so (Kandel et al. 1983; Ocorr et al. 1985; Abrams et al. 1991, 1998; Yovell et al. 1992). What voltage-dependent $\mathrm{Ca}^{2+}$ current might be involved? Two voltage-dependent $\mathrm{Ca}^{2+}$ currents were initially characterized in Aplysia: a rapidly inactivating, dihydropyridine-insensitive, high voltage activated current and a slowly inactivating, dihydropyridine-sensitive, L-type current (Edmonds et al. 1990). The dihydropyridine-insensitive current is activated by action potentials and is important for normal synaptic transmission and several types of plasticity including presynaptic inhibition, homosynaptic depression, and normal presynaptic facilitation (Edmonds et al. 1990; Eliot et al. 1993). However, that current would be poorly activated by the depolarizing voltage clamp pulse that we found can also act as the CS. In contrast, the dihydropyridine-sensitive current is poorly activated during action potentials and is not important for normal synaptic transmission or for several types of plasticity including activity-dependent facilitation with a train of action potentials as the CS (Edmonds et al. 1990; Eliot et al. 1993, 1994). However, that current is activated by a $20 \mathrm{mV}$ depolarizing pulse from a holding potential of $-50 \mathrm{mV}$ (Edmonds et al. 1990) and it or some other low voltage activated current (Lacinová 2005) could allow $\mathrm{Ca}^{2+}$ influx when the voltage clamp pulse is the CS (Fig. 4). Thus, different $\mathrm{Ca}^{2+}$ currents may be activated when the CS is a train of action potentials or a depolarizing pulse, but in both cases, the resultant $\mathrm{Ca}^{2+}$ influx could act to prime the adenylyl cyclase during activity-dependent facilitation.

\section{Materials and Methods}

The methods were similar to those of previous experiments on activity-dependent presynaptic facilitation (Hawkins et al. 1983). 
Hermaphroditic Aplysia californica weighing 100-300 g (supplied by Pacific Biomarine) were anesthetized with isotonic $\mathrm{MgCl}_{2}$, and the central nervous system was dissected out (with or without the tail) and pinned to the Sylgard (Dow Chemical) floor of a dish filled with circulating artificial seawater (ASW, Instant Ocean) at room temperature. The abdominal ganglion was partially desheathed, and two LE siphon SNs were impaled with singlebarreled glass microelectrodes filled with $2.5 \mathrm{M} \mathrm{KCl}(\sim 10 \mathrm{M} \Omega$, shielded with parafilm and aluminum foil) connected to two Dagan 8100 single electrode voltage clamps run on the same clock. The switching frequency was $3 \mathrm{kHz}$, and the capacity compensation, phase, and gain were adjusted at near maximum to produce the best square wave as seen at the output of the headstage without ringing (Halliwell and Adams 1982). The efficacy of the voltage clamp was confirmed by impaling the same neuron with two microelectrodes, one under voltage clamp and one under the current clamp, and checking that the voltage and current readings of the two electrodes agreed.

During training, there were five trials with a 5 min intertrial interval, during which the amplifier was switched to current-clamp mode. On each trial, a train of six action potentials at $10 \mathrm{~Hz}$ (the conditioned stimulus or CS) was produced in each SN by brief depolarizing pulses. The CS in one neuron (the paired neuron) started $0.5 \mathrm{sec}$ before a $1.5 \mathrm{sec}$ train of $20 \mathrm{~Hz}$ (Figs. 1-3) or $10 \mathrm{~Hz}$ (Fig. 4) shocks to the posterior pedal nerves (the unconditioned stimulus or US), whereas the CS in the other neuron (the unpaired neuron) started $2.5 \mathrm{~min}$ after the US. Each neuron was tested under voltage clamp $\sim 5 \mathrm{~min}$ before and $5 \mathrm{~min}$ after training. Then $10^{-4} \mathrm{M}$ serotonin (5HT) was added to the bath and the neurons were tested again 5 min later. During testing the current (leakage corrected) in each neuron was measured during $500 \mathrm{msec}$ voltage pulses of $-20,20$, and $40 \mathrm{mV}$ from a holding potential of $-50 \mathrm{mV}$, first in ascending and then in descending order, and the two measurements for each voltage pulse were averaged. The $-20 \mathrm{mV}$ pulse was used to estimate leakage current. The two neurons were tested once every $20 \mathrm{sec}$ I sec apart, counter balanced for the order. In some experiments (Fig. 4) the amplifier was kept in voltage-clamp mode during training and the CS was a $500 \mathrm{msec}$ voltage pulse of either 20 or $40 \mathrm{mV}$ (in interdigitated experiments) from a holding potential of $-50 \mathrm{mV}$. In those experiments, there was no $40 \mathrm{mV}$ pulse during testing and no $5 \mathrm{HT}$.

Experiments comparing paired and unpaired SNs in the same preparation (Figs. 1, 4) were analyzed with paired $t$-tests using Statistica software. Experiments with paired, unpaired, and serotonin training and two levels of voltage step during testing had a full factorial within subjects design, and were analyzed with two-way repeated measures ANOVAs with training (either $\mathrm{P}, \mathrm{UP}$, and the average 5HT, Fig. $3 \mathrm{~A}$ or P-UP and the average 5HT, Fig. 3B) and voltage step (20 and $40 \mathrm{mV}$ ) as the factors. The ANOVAs were then repeated after scaling the training groups to the same overall mean to test for differences in the shapes of the curves (the training $\times$ voltage step interaction).

\section{Acknowledgments}

We thank Steve Siegelbaum for his comments. This research and preparation of the manuscript were supported by National Institutes of Health (NIH) grants MH26212 and NS083690.

\section{References}

Abrams TW, Karl KA, Kandel ER. 1991. Biochemical studies of stimulus convergence during classical conditioning in Aplysia: dual regulation of adenylate cyclase by $\mathrm{Ca}^{2+} /$ calmodulin and transmitter. J Neurosci 11: 2655-2665. doi:10.1523/JNEUROSCI.11-09-02655.1991

Abrams TW, Yovell Y, Onyike CU, Cohen JE, Jarrard HE. 1998. Analysis of sequence-dependent interactions between calcium and transmitter stimuli in activating adenylyl cyclase in Aplysia: possible contributions to CS-US sequence requirement during conditioning. Learn Mem 4: 496-509. doi:10.1101/lm.4.6.496

Antonov I, Antonova I, Kandel ER, Hawkins RD. 2001. The contribution of activity-dependent synaptic plasticity to classical conditioning in Aplysia. J Neurosci 21: 6413-6422. doi:10.1523/JNEUROSCI $.21-16-06413.2001$
Antonov I, Antonova I, Kandel ER, Hawkins RD. 2003. Activity-dependent presynaptic facilitation and Hebbian LTP are both required and interact during classical conditioning in Aplysia. Neuron 37: 135-147. doi:10 $.1016 /$ S0896-6273(02)01129-7

Antonov I, Ha T, Antonova I, Moroz LL, Hawkins RD. 2007. Role of nitric oxide in classical conditioning of siphon withdrawal in Aplysia. $J$ Neurosci 27: 10993-11002. doi:10.1523/JNEUROSCI.2357-07.2007

Bao J-X, Kandel ER, Hawkins RD. 1998. Involvement of presynaptic and postsynaptic mechanisms in a cellular analog of classical conditioning at Aplysia sensory-motor neuron synapses in isolated cell culture. $J$ Neurosci 18: 458-466. doi:10.1523/JNEUROSCI.18-01-00458.1998

Baxter DA, Byrne JH. 1989. Serotonergic modulation of two potassium currents in the pleural sensory neurons of Aplysia. J Neurophysiol 62: 665-679. doi:10.1152/jn.1989.62.3.665

Byrne JH, Kandel ER. 1996. Presynaptic facilitation revisited: state and time dependence. J Neurosci 16: 425-435. doi:10.1523/JNEUROSCI .16-02-00425.1996

Clark GA, Hawkins RD, Kandel ER. 1994. Activity-dependent enhancement of presynaptic facilitation provides a cellular mechanism for the temporal specificity of classical conditioning in Aplysia. Learn Mem 1: 243-257.

Edmonds B, Klein M, Dale N, Kandel ER. 1990. Contributions of two types of calcium channels to synaptic transmission and plasticity. Science 250: 1142-1147. doi:10.1126/science.2174573

Eliot LS, Kandel ER, Siegelbaum SA, Blumenfeld H. 1993. Imaging terminals of Aplysia sensory neurons demonstrates role of enhanced $\mathrm{Ca}^{2+}$ influx in presynaptic facilitation. Nature 361: 634-637. doi:10.1038/361634a0

Eliot LS, Hawkins RD, Kandel ER, Schacher S. 1994. Pairing-specific, activity-dependent presynaptic facilitation at Aplysia sensory-motor neuron synapses in isolated cell cultures. J Neurosci 14: 368-383. doi:10 .1523/JNEUROSCI.14-01-00368.1994

Goldsmith BA, Abrams TW. 1992. cAMP modulates multiple $\mathrm{K}^{+}$currents, increasing spike duration and excitability in Aplysia sensory neurons. Proc Natl Acad Sci 89: 11481-11485. doi:10.1073/pnas.89.23.11481

Halliwell JV, Adams PR. 1982. Voltage-clamp analysis of muscarinic excitation in hippocampal neurons. Brain Res 250: 71-92. doi:10.1016/ 0006-8993(82)90954-4

Hawkins RD, Byrne JH. 2015. Associative learning in invertebrates. Cold Spring Harb Perspect Biol 7: a021709. doi:10.1101/cshperspect.a021709

Hawkins RD, Abrams TW, Carew TJ, Kandel ER. 1983. A cellular mechanism of classical conditioning in Aplysia: activity-dependent amplification of presynaptic facilitation. Science 219: 400-405. doi:10.1126/science .6294833

Hawkins RD, Mayford M, Kandel ER. 2017. A comparative analysis of the molecular mechanisms contributing to implicit and explicit memory storage in Aplysia and in the hippocampus. Mechanisms of memory (ed. Sara, SJ), Vol. 4 of Learning and memory: a comprehensive reference, 2 nd ed. (ed. Byrne, JH), pp. 5-32. Academic Press, Oxford, UK.

Hochner B, Kandel ER. 1992. Modulation of a transient $\mathrm{K}^{+}$current in the pleural sensory neurons of Aplysia by serotonin and cAMP: implications for spike broadening. Proc Natl Acad Sci 89: 11476-11480. doi:10.1073/ pnas.89.23.11476

Hu JY, Chen Y, Schacher S. 2007. Protein kinase C regulates local synthesis and secretion of a neuropeptide required for activity-dependent long-term synaptic plasticity. J Neurosci 27: 8927-8939. doi:10.1523/ JNEUROSCI.2322-07.2007

Hu J, Adler K, Farah CA, Hastings MH, Sossin WS, Schacher S. 2017a. Cell-specific PKM isoforms contribute to the maintenance of different forms of persistent long-term synaptic plasticity. J Neurosci 37: 27462763. doi:10.1523/JNEUROSCI.2805-16.2017

Hu J, Ferguson L, Adler K, Farah CA, Hastings MH, Sossin WS, Schacher S. $2017 \mathrm{~b}$. Selective erasure of distinct forms of long-term synaptic plasticity underlying different forms of memory in the same postsynaptic neuron. Curr Biol 27: 1888-1899.e4. doi:10.1016/j.cub.2017.05.081

Kandel ER, Abrams T, Bernier L, Carew TJ, Hawkins RD, Schwartz JH. 1983. Classical conditioning and sensitization share aspects of the same molecular cascade in Aplysia. Cold Spring Harb Symp Quant Biol 48: 821830. doi:10.1101/SQB.1983.048.01.085

Kelso SR, Ganong AH, Brown TH. 1986. Hebbian synapses in hippocampus. Proc Natl Acad Sci 83: 5326-5330. doi:10.1073/pnas.83.14.5326

Klein M, Camardo J, Kandel ER. 1982. Serotonin modulates a specific potassium current in the sensory neurons that show presynaptic facilitation in Aplysia. Proc Natl Acad Sci 79: 5713-5717. doi:10.1073/ pnas.79.18.5713

Lacinová L. 2005. Voltage-dependent calcium channels. Gen Physiol Biophys 24(Suppl): 1-78.

Lin XY, Glanzman DL. 1994a. Hebbian induction of long-term potentiation of Aplysia sensorimotor synapses: partial requirement for activation of a NMDA-related receptor. Proc R Soc Lond B 255: 215-221. doi:10.1098/ rspb.1994.0031 
Lin XY, Glanzman DL. 1994b. Long-term potentiation of Aplysia sensorimotor synapses in cell culture: regulation by postsynaptic voltage. Proc R Soc Lond B 255: 113-118. doi:10.1098/rspb.1994.0016

Murphy GG, Glanzman DL. 1996. Enhancement of sensorimotor connections by conditioning-related stimulation in Aplysia depends on postsynaptic $\mathrm{Ca}^{2+}$. Proc Natl Acad Sci 93: 9931-9936. doi:10.1073/pnas 93.18.9931

Murphy GG, Glanzman DL. 1997. Mediation of classical conditioning in Aplysia californica by long-term potentiation of sensorimotor synapses. Science 278: 467-471. doi:10.1126/science.278.5337.467

Murphy GG, Glanzman DL. 1999. Cellular analog of differential classical conditioning in Aplysia: disruption by the NMDA receptor antagonist DL-2-amino-5-phosphonovalerate. J Neurosci 19: 10595-10602. doi:10 .1523/JNEUROSCI.19-23-10595.1999

Ocorr KA, Walters ET, Byrne JH. 1985. Associative conditioning analog selectively increases cAMP levels of tail sensory neurons in Aplysia. Proc Natl Acad Sci 82: 2548-2552. doi:10.1073/pnas.82.8.2548

Schacher S, Wu F, Sun ZY. 1997. Pathway-specific synaptic plasticity: activity-dependent enhancement and suppression of long-term heterosynaptic facilitation at converging inputs on a single target. $J$ Neurosci 17: 597-606. doi:10.1523/JNEUROSCI.17-02-00597.1997

Shuster MJ, Camardo JS, Siegelbaum SA, Kandel ER. 1985. Cyclic AMP-dependent protein kinase closes the serotonin-sensitive $\mathrm{K}^{+}$ channels of Aplysia sensory neurones in cell-free membrane patches. Nature 313: 392-395. doi:10.1038/313392a0
Walters ET, Byrne JH. 1983. Associative conditioning of single sensory neurons suggests a cellular mechanism for learning. Science 219: 405408. doi:10.1126/science.6294834

Wigström H, Gustafsson B, Huang YY, Abraham WC. 1986. Hippocampal long-term potentiation is induced by pairing single afferent volleys with intracellularly injected depolarizing current pulses. Acta Physiol Scand 126: 317-319. doi:10.1111/j.1748-1716.1986.tb07822.x

Yang Q, Kuzyk P, Antonov I, Bostwick C, Kohn AB, Moroz LL, Hawkins RD. 2015. Hyperpolarization-activated, cyclic nucleotide-gated cation channels in Aplysia: contribution to classical conditioning. Proc Natl Acad Sci 112: 16030-16035. doi:10.1073/pnas.1501731113

Yang Q, Antonov I, Castillejos D, Nagaraj A, Bostwick C, Kohn A, Moroz LL, Hawkins RD. 2018. Intermediate-term memory in Aplysia involves neurotrophin signaling, transcription, and DNA methylation. Learn Mem 25: 620-628. doi:10.1101/lm.047977.118

Yovell Y, Kandel ER, Dudai Y, Abrams TW. 1992. A quantitative study of the $\mathrm{Ca}^{2+} /$ calmodulin sensitivity of adenylyl cyclase in Aplysia, Drosophila, and rat. J Neurochem 59: 1736-1744. doi:10.1111/j.1471-4159.1992 .tb11005.x

Received May 6, 2019; accepted in revised form August 20, 2019. 


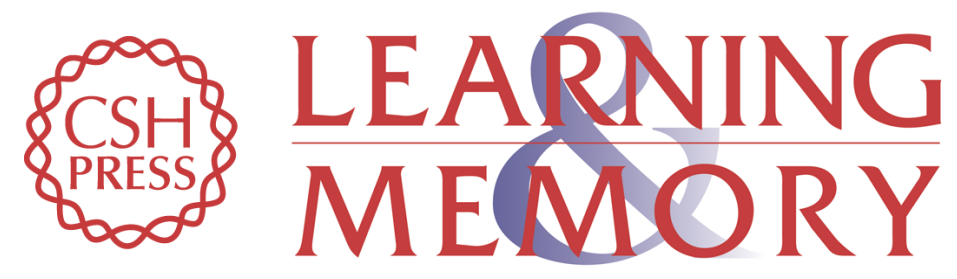

\section{Comparison of the ionic currents modulated during activity-dependent and normal presynaptic facilitation}

Robert D. Hawkins and Eric R. Kandel

Learn. Mem. 2019, 26:

Access the most recent version at doi:10.1101/lm.049916.119

References This article cites 37 articles, 26 of which can be accessed free at: http://learnmem.cshlp.org/content/26/11/449.full.html\#ref-list-1

Creative This article is distributed exclusively by Cold Spring Harbor Laboratory Press for the Commons License first 12 months after the full-issue publication date (see

http://learnmem.cshlp.org/site/misc/terms.xhtml). After 12 months, it is available under a Creative Commons License (Attribution-NonCommercial 4.0 International), as described at http://creativecommons.org/licenses/by-nc/4.0/.

Email Alerting Receive free email alerts when new articles cite this article - sign up in the box at the Service top right corner of the article or click here. 